Competing Interests:

None declared.

Ethical approval:

Not applicable.

Author's contribution: $\mathrm{EH}^{1}$ is the primary author of this paper and prepared the manuscript in entirety.

Funding:

None declared.

Acknowledgements: $E H^{1}, L G^{2}, L R^{3}$ \&

$\mathrm{RL}^{4}$ would like to thank: Alexander Barnes, Martin Blatchford, Dave Birch, Mike Flower, Rachel

Finley, Iqbal Gandham, Bhavin Kotecha, Peeter Kokek, Michael Mainelli, Catherine McBride, Sue Milton, Stephen Talbot, and Naseem Naqui and Jane Thomason from the British Blockechain Association, for their advice about blockechain and/ or comments on draft versions of the paper.

ISSN Print: 2516-3949

\title{
Unlocking Blockchain:
}

https://doi.org/10.31585/jbba-1-2-(6)2018

\section{Embracing New Technologies to drive Efficiency and Empower the Citizen}

Eddie Hughes ${ }^{1}$, Luke Graham ${ }^{2}$, Lee Rowley ${ }^{3}$, Rebecca Lowe ${ }^{4}$

${ }^{1,2,3}$ Member of Parliament, UK

${ }^{4}$ Director, FREER, UK

Correspondence: rebecca@freeruk.com

Received: 25 June 2018 Accepted: 4 July 2018 Published: 5 July 2018

\begin{abstract}
With their innovative and fundamentally liberalising approach to data storage, distributive ledger technologies (DLTs) like blockchain — and other associated technologies offer immense benefits to both the public and private sectors, not least in terms of upping efficiency. Lovers of freedom should also note, however, that they offer an important chance to empower individuals in their necessary engagements with the state, and to rebuild societal trust for the common good. In this paper, we propose the establishment of a UK-based international blockchain competition, and a public-facing 'Chief Blockchain Officer'. We also propose a UK 'blockchain departmental target': a long-term aim for government departments to make a $1 \%$ efficiency saving by embracing blockchain and other associated innovative technologies. A renewed UK focus on efficiency and the opportunities of new technology would be inspirational, and we look forward to discussing these proposals, and carrying out further research into DLTs.
\end{abstract}

Keywords: chief blockchain officer, empower, citizen, savings, DLT, trust

\section{Introduction}

\section{Tackling the trust deficit}

In a free society, the bonds of trust bring responsible individuals together into chosen community. Freedom and trust go hand in hand. Yet, in the wake of the 2008 financial crash, and a series of serious public scandalsranging from the illegal misuse of parliamentary expense accounts, to claims of harassment and abuse against charity workers-is it any surprise that our institutions are increasingly viewed with suspicion? After what has felt like a never-ending litany of betrayals of trust and instances of overreach, the political and financial establishments, companies, and voluntary organisations that were once seen as pillars of the community, are often now held in little more than near contempt by citizens. Bad behaviour not only harms those directly involved; the trust deficit is destructive to democratic society.

Alongside a national need to redress wrongs, it also falls to policymakers, as leaders, to seek to rebuild societal trust. A long-term political approach must put people first, and at the heart of the decision-making that affects their everyday lives. This is something that should go without saying - not least to those of us who believe that the state should be limited and justified-but it hasn't always been the case. We also need to emphasise that extensive state regulation did not deter these scandals, and that we should begin, with urgency, to explore how new technologies might help us to establish lighter-touch, yet more effective, ways of preventing institutions exploiting their power. There is a substantial trust deficit to tackle, and an obvious place to begin is with data.

Data is quickly becoming one of the most valuable resources in the world. Roughly 90 per cent of the world's data has been created in the past two years. ${ }^{1}$ Some of the most prominent companies todayGoogle, Microsoft, Facebook, Twitter-are world leaders in data collection and storage. And the state holds vast amounts of data on each of us. Data is a powerful tool, however, and without secure storage and adequate checks and balances, the data subject-who, too often, is not the data holder - can be at significant risk of ceding too much power and information to others.

Own, see, hold, control 
Trust in public services grows as they become more transparent. Citizens should be able to own, see, hold, and control the use of their own data - the data that others are so keen to access, and that our security and wellbeing increasingly depends upon. In the past, the use of data was too often hidden behind organisations' firewalls, out of sight of the data's subjects. New technologies, however, such as blockchain, allow for more subject control, more transparency, and less need for centralised services. These new technologies provide greater technical resilience and security, too. Could technologies like blockchain help to restore our society's lost trust in the institutions of government, and pave the way to greater individual autonomy? Could public encouragement of the entrepreneurial use of such technology lead to significant efficiency savings, not least across government departments? Could embracing blockchain's development provide fresh energy and impetus for improvement and innovation using other methods of data storage and wider technological advancement? This paper seeks to begin to answer those questions, and more.

\section{BLOCKCHAIN: A SHORT EXPLANATION}

\section{What and How}

The concept of blockchain was first conceived in a 2008 white paper, written by an anonymous creator (or, possibly, creators), using the pseudonym 'Santoshi Nakamoto', who referred to a 'chain of blocks'. Since then, blockchain has become best known for underpinning the cryptocurrency, Bitcoin-an electronic peer-to-peer cash system designed to challenge the failures of the banks. While crypto-assets are still evolving, and finding their feet, blockchain technology has been widely recognised for its other potential uses, which are now being enthusiastically explored by financial institutions, businesses, and governments, worldwide.

Blockchains are a subset of distributed ledger technologies (DLTs), which are also known, in the business world, as shared ledger technologies (SLTs). Traditional ledgers take the form of a 'master version', which is held by one owner, and which everyone else involved can either access, or ask for a copy when needed. DLTs, however, take the form of multiple copies of the same thing, which are all updated whenever any user updates their copy. Effectively, anything that is a ledger can be adapted into this new form, thanks to technological progress in processing power, encryption, networking, and coding. Blockchains can be public or private, or permissioned or permissionless. For example, the Bitcoin blockchain is public and permissionless, whereas 'Ethereum with Casper' will be public but permissioned.

Blockchains distribute updated copies of the ledger to participants after a block relating to a transaction has been created, in near-real time (blocks can take ten minutes to create, but this depends upon the blockchain being used). Network participants have their own private 'keys', which act as personal digital signatures to sign transactions. Transactions are grouped into new blocks, and connected to previously verified blocks (each block is given a fingerprint called a 'hash'), to form an immutable chain, which records the entire history of transactions - hence the name 'block chain'. Blockchain and other associated technologies have the potential to empower individuals, not least by ensuring data integrity and by removing the need for it to be held centrally_although private blockchains can be centralised.

The records on a blockchain are secured through the use of cryptography. Varying methods of cryptography are used, and the strength of the techniques employed is a key reason why blockchain is increasingly used by military organisations. There are many different specific blockchain systems, encryptions, and applications. But the emphasis of this paper will be more general: it will focus on why supporters of classical liberalism-lovers of freedom-should embrace these kinds of new technology.

\section{The primary benefits}

The primary benefits of blockchain are general accepted to be security - in terms of transparency, immutability, and decentralisation-and efficiency, particularly regarding the elimination of the need for trusted third parties.

Blockchain provides traceability and clear provenance. The blockchain holds all of the data from the start of the transaction, so the full history of any asset that is on the ledger can be known. There is no need to audit vast amounts of data, as the blockchain itself is the audit trail.

In the case of a central database, the security and trustworthiness of the data's controller are vitally important, because they have full control and responsibility if the data is hacked, altered, or destroyed. Blockchain, however-by allowing data to be held on a distributed platform, and by allowing participants to see if transactions have been amended — cannot be easily manipulated. This makes fraud almost impossible, data loss unlikely, and offers an unparalleled rise in trustworthiness.

The way in which blockchain cuts out the 'middle man' means that connections are made directly, peer-to-peer. This has immense potential to increase trust, to afford more control to the individuals 
participating in transactions, and to reduce costs significantly. (The use of blockchain itself does entail costs, however, including expenses related to keeping the system secure.)

An additional feature, introduced by the leading open-sourced blockchain-based software platform, Ethereum, is the 'smart contract', which enables selfexecuting code: upon the successful fulfilment of pre-set criteria, an automatic outcome is actioned. A smart contract tends to be a simple piece of code, which follows auditable and transparent rules, and is usually validated by a lawyer. Again, no third parties are required in transactions, so, if set up, you could buy a car directly from a car manufacturer, for instance: the ownership of the vehicle could be directly moved to you upon your payment of funds, and the vehicle registration documents could be altered on the blockchain — without any need for a bank or a card company, a central registration, or a car dealership. Smart contracts can also provide mechanisms for handling disputes.

Current challenges to the large-scale uptake of blockchain include costs and barriers to scaling. Not only are there significant implementation costs, but long-run costs in storage and electricity are likely to be high, too. As a recent Forbes article explained, ${ }^{2}$ much of the excitement surrounding blockchain ignores the future costs of storage and electricity. Storage costs are modest to begin with, but increase vastly over time as the quantity of transactional information increases. Technological advancement will, no doubt, address these problems in due course, but they remain current challenges nonetheless.

\section{Application opportunities}

Over the past decade, research into the opportunities that blockchain and associated technologies might offer has been carried out, internationally, by various sectors, ranging from the retail industry to banking. Here is a selection of key recent findings:

- The retail industry is positive about the cost-saving implications of blockchain's capacity to automate labour-intensive operational tasks. In a 2017 global survey of retail professionals, 82 percent of respondents were confident of blockchain's ability to reduce these costs. ${ }^{3}$

- In the financial sector, blockchain is seen as presenting a significant opportunity for investment banks to reduce their cumbersome infrastructure costs. An Accenture report in 2017 indicated that savings for eight of the largest investment banks could average 30 per cent, or around

\section{\$8-\$12bn in savings. ${ }^{4}$}

- For banks, the infrastructure costs associated with cross border payments, securities trading, and regulatory compliance could be reduced by $\$ 15-20$ billion per annum by 2022 through the use of DLT, according to a 2015 Santander report on Fintech. ${ }^{5}$

In Sweden, the use of blockchain technologies in land registries is predicted to save over $\$ 100$ million per year, through reduced paperwork and fraud elimination, as well as faster transactions, according to the consultancy firm Kairos Future. ${ }^{6}$ Blockchain potentially has further productivity and environmental benefits. The Dubai Blockchain Strategy's 'first pillar', which focuses on government efficiency, predicts the reallocation of up to 25.1 million economically productive hours through reduced document processing times, as well as the elimination of 114 MTons of CO2 emissions through fewer trips.?

Blockchain has important implications for the funding of global development.

Researchby Dr Jane Thomason and Lauren Weir has stated that, through the use of blockchain, an additional $\$ 15$ billion of global aid could be made available through a 10 per cent saving in verification and networking costs, with a much larger figure entirely possible. ${ }^{8}$

\section{Individual freedom in an algorithmic world}

Blockchain technology clearly offers immense potential benefits to the public and private sectors, alike. Freedom-lovers may be in need of reassurance, however, that its use won't lead to citizens unthinkingly ceding their self-determining power to decisionmaking algorithms. Increasingly, algorithms appear almost everywhere.' They are used by Facebook to promote the news of those certain friends who have been assessed to be of the most interest to us. They are used by Spotify to make suggestions about what music we should listen to. They are used by Google to return the search results that have been determined most relevant to our inquiries. And, the more we engage, the more these algorithms restrict our choices, as they give us what they 'think' we want. Unsurprisingly, this can create an echo-chamber effect, or environments in which 'fake news' can easily spread.

But blockchain should not be about 'handing over' data - and, therefore, power- to big companies, or to the state. It should not be used to attempt to control data through a centralised system. Rather, its true positive revolutionary potential is in empowering the owners and the users of that data, thereby promoting individual autonomy and increasing trust. So, it could 
be argued, for example, that the government should not create a cryptocurrency in which every penny can be traced, but rather that it should use the opportunities of these new technologies to forge a banking system that decreases costs, inefficiencies, and the need for 'middle-men' intermediaries. The state should focus its attention on using blockchain to enable social freedom, on cutting the costs of economic activity, and on rebuilding societal trust for the common good.

\section{BLOCKCHAIN: ABROAD}

\section{The Estonian model}

Estonia has quickly become known as a world leader in distributed ledger technology (DLT), having allegedly begun testing blockchain in $2008,{ }^{10}$ and having used it in both the public and private sectors for the last six years.

Since 2012, blockchain has been in operational use in Estonia's registries, such as national health, judicial, legislative, security and commercial code systems, with plans to extend its use to other spheres such as personal medicine, cyber security and data embassies. ${ }^{11}$

The specific technology that Estonia uses-KSI Blockchain-was created by a company called Guardtime, with 'the goal of creating a formally verifiable security system for the Estonian Government'. ${ }^{12}$ Guardtime's technology is also used by various other governments and organisations. Earlier this year, Guardtime 'planned and executed a custom cyber exercise' for the UK's civil nuclear sector. ${ }^{13}$

When attempting to assess the impact that the wholesale take-up of blockchain has had on Estonia, it is important to recognise that the country has linked its use to other technologies. Adopting some of these technologies could straightforwardly revolutionise British life for the better; others come with significant challenges, including risks pertaining to individual freedom.

\section{X-Road}

In Estonia, 99 per cent of government services are digitally linked through an 'interoperability platform' called X-Road, which is underpinned by blockchain:

[All] information is held in a distributed data system and can be exchanged instantly upon request, providing data exchange $24 / 7$. Linking up thousands of databases, it saves approximately more than 820 years of working time for the state and citizens annually, while having over 900 organizations and enterprises in Estonia using $\mathrm{X}$-Road daily. However, these savings are the result of only five per cent of all queries done via X-Road. 95 per cent of the savings are difficult to measure directly, as they occur automatically, thanks to the machine-tomachine data exchange. Therefore saving 820 years of working time a year is just a tip of the iceberg [...] Estonia's e-solution environment includes a full range of services of public and private sector for the general public, and since each service has its own information system, they all use X-Road. To ensure integrity, all data exchange over X-Road is signed, timestamped and chained together in several ways. ${ }^{14}$

It is claimed that, thanks to this substantial technological infrastructure, the 'only three things' that cannot now be done online in Estonia are purchasing property, getting married, and getting divorced. ${ }^{15}$ The efficiency savings in this overall model seem to be unsurprisingly extensive. The current Estonian Prime Minister, Juri Ratas, told a technology conference in 2017 that the 'digital solutions of e-Estonia make our daily life a great deal easier and more efficient. For citizens, for companies and for the state. It allows us to save two per cent of GDP every year. ${ }^{16}$ This two per cent figure has been widely repeated, although it is sometimes tied to more specific policy changes (see below).

\section{Digital signatures $\&$ identity}

Estonia's Digital Signature Act was passed in 2000, making digital signatures equivalent in law to handwritten ones, subject to a number of checks and balances. This technology has vast potential to cut costs, reduce fraud, and empower individuals; used in collaboration with blockchain, it can increase security and enhance privacy. In 2016, during a talk at the International Peace Institute, Estonia's former Prime Minister, Taavi Roivas, claimed that 'Estonia saves two per cent of GDP by signing things digitally'. ${ }^{17}$ In the same year, on the Daily Show, Roivas also stated that digital reforms had made it the case that it took Estonians only three minutes, on average, to file their tax returns. ${ }^{18}$ Some have contended that it is this new efficiency in tax collection, specifically, that has driven the GDP savings related to the country's technological overhaul.

We must note, however, that, in Estonia, digital signatures are linked to ID cards, mobile-IDs, or Smart-IDs - these give every citizen their unique cryptography keys. ${ }^{19}$ And, that, last year, the country had a notable 'security crisis' concerning its ID cards. ${ }^{20}$ (Although it has been argued that the vulnerability that allowed the crisis to happen related to insufficient precautions around the keys, rather than the software.)

The introduction of any kind of mandatory state-run ID card is neither a viable nor a desirable solution for the UK. The public opposes the idea as a serious threat to privacy and a contravention of the fundamental liberal principles upon which the UK is built. It is important to recognise the difference between digital 
identity infrastructure and a state ID-card system, however. There is no time here to analyse the freedombased arguments for and against the introduction of the type of digital identity infrastructure that would aim to empower the individual by reducing their dependence on the state-and the potential benefits for people who do not currently have identity documents-but it is clearly a topic for further discussion. Key questions here relate to the difference between confidentiality and integrity (blockchain was created to solve problems related to the latter, rather than the former), and the difference between privacy and anonymity.

Digital signatures can be used outside of an IDcard system, however. The UK's Electronic Communications Act, which was granted royal assent in 2000 , made provision to 'facilitate the use of electronic communications and electronic data storage'. Part II of the act confirms the legal status of 'electronic signatures and related certificates'. ${ }^{21}$

Approached with the aim of increasing trust and empowering citizens, rather than making them subject to a state-organised system, the combination of blockchain, digital signatures, and related other new technologies, clearly offer untapped opportunities for the UK.

\section{Data ownership}

Estonia's embrace of the new technologies above is premised on a fundamental principle that a person's own data belongs to that person, rather than to whomever might hold their data. In countries where that is not explicitly the case, not only do fundamental questions arise about rights, but people also often find it hard to access their personal data. Health data is a useful example of this. In most places, few people can say precisely where their medical records are located, and who has looked at them. But Estonians can log into their own records to see which medical professionals have accessed their data, and when; they can also lock people out of seeing their data, too. ${ }^{22}$ It should also be noted that, in the Estonian model, apparently it is usually the access to data-rather than the data itselfthat is stored on the blockchain. In a world in which one's data, increasingly, is a substantial personal asset, big questions lies ahead of us regarding ownership and property rights.

Nonetheless, the possibility of combining blockchain, AI, cryptography, and other new technologies has great potential for efficiency savings. And, when designed around the needs of individuals, could revolutionise the way we interact with the state. The central argument of this paper, therefore, is that the state must not be allowed to use such technology to intrude into the lives of individuals-but rather that the technology should be used to empower individuals in their necessary engagements with the state.

\section{Dubai and elsewhere: comparisons, competitions, and challenges}

The UAE, the USA, ${ }^{23}$ Singapore, ${ }^{24}$ and other nations are also making strong headway with DLTs. It has been reported that the UAE's Prime Minister has claimed that the use of blockchain technology could 'contribute to saving AED 11 billion (approximately USD \$3 billion) spent annually on document processing alone'. ${ }^{25}$ Dubai has famously set its sights on having 'the first blockchain-powered government by 2020 '. ${ }^{26}$ The Dubai Blockchain Strategy revolves around three main pillars: government efficiency, industry creation, and international leadership. ${ }^{27}$ A 'Global Blockchain Council' has been set up by the Dubai Future Foundation, with the council's members including leading industry professionals and government representatives. The council discusses policies and regulation, and its aim is to highlight the implications of this innovation on the future of business and finance sectors, and its role in facilitating transactions within the various sectors of financial and non-financial sectors as well as to increase efficiency and reliability levels. ${ }^{28}$

By embracing 'smart technology', Dubai is aiming for a completely paperless government by 2021, which would lead to substantial savings and environmental benefits. ${ }^{29}$ In 2017, the Dubai Land Department claimed to have become 'the world's first government entity to adopt blockchain technology'30 - its system uses a 'smart and secure database to record all real estate contracts', as well as linking them up to Dubai's Electricity and Water Authority and telecommunications system. ${ }^{31}$

A global 'Blockchain Challenge' is also used to try to entice the best entrepreneurs to develop their solutions in Dubai. While Innovate UK recently ran an initiative offering businesses and research groups the chance to gain funding for blockchain-based projects, ${ }^{32}$ a similarly extensive international competition should be set up in the UK to drive homegrown entrepreneurship, and to entice leading global players to develop technology here. Ideally, this should be established in collaboration with leading British universities, and funded by businesses that would benefit from improved national technological standards. Blockchain and associated technologies clearly offer an immense opportunity for the UK. Less than a decade after the first 'application on the blockchain'-bitcoin-mass awareness of the technology is already here, implying that mass adoption could be not too far behind. If the UK wants to stay at the forefront of fintech and finance, particularly, the value of DLT innovation must not be overlooked. 


\section{BLOCKCHAIN: AT HOME}

\section{Departmental application}

In December 2015, the UK government's Office for Science published a paper entitled Distributed Ledger Technology: beyond blockchain, which recognised the advantages of these 'disruptive' technologies. The paper was a promising start, and soon after its publication, a London-based start-up called Credits became the first DLT company to be accepted on to the list of government-approved suppliers. CityAM reported at the time that this meant that 'any public sector body-from the NHS to the department for work and pensions - could in theory begin creating digital services built on blockchain from today, ${ }^{33}$ While the government's approval of the start-up showed a commitment to using this type of technology in public services, it should be noted that it has since been reported that Credits has 'ceased operations'. ${ }^{34}$

Written parliamentary answers provide some detail about the government's relevant 'proof of concept' projects currently underway for various departments: from traceability of food throughout the supply chain, to giving patients greater control over who can access their health records through the use of decentralised systems. In February 2018, the Treasury Committee launched an inquiry into digital currencies and distributed ledger technology. ${ }^{35}$ HM Revenue and Customs is also considering the use of blockchain, alongside other technical options, for tax and customs and excise systems. In May 2016, the Parliamentary Office of Science and Technology (POST) produced a small note on FinTech, focusing on four emerging areas, of which DLT was one. ${ }^{36}$ Then, in January 2018, POST set out a 'topics of interest' document, which listed DLTs as needing further exploration. ${ }^{37}$ The Department for Work and Pensions has held a trial with GovCoin on how blockchain might help with welfare payments, although written answers show that the pilot came to an end last year, and that the department has no further intention of working with GovCoin.

The total action on DLT within UK government departments appears limited, therefore, and, for the most part, investigations have been focused on its underpinning of Bitcoin. The emphasis, so far, seems to have been on assessing blockchain's potential role in financial matters, rather than public administration.

\section{Recent developments}

At the London Blockchain Conference, in April of this year, however, the Secretary of State for Culture, Media and Sport, Matt Hancock, emphasised that 'blockchain technology holds real potential to make Government services more efficient'. He reiterated the 2017 Digital Strategy's commitment to blockchain trials, and claimed there to be 'wide interest across Government in deploying blockchain to tackle a wide range of issues, including from Defra, the Ministry of Justice, DFID, HMRC, and BEIS'. ${ }^{38}$ It is also encouraging that, again in April, the UK signed a declaration on the establishment of a European Blockchain Partnership.

The Partnership will be a vehicle for cooperation amongst Member States to exchange experience and expertise in technical and regulatory fields and prepare for the launch of EU-wide blockchain applications across the Digital Single Market for the benefit of the public and private sectors. This should ensure that Europe continues to play a leading role in the development and roll-out of blockchain technologies. ${ }^{39}$

\section{Coordination}

We clearly need more national urgency in this area, however. Aside from the obvious advantages that DLT and related technologies offer business, they also provide the perfect opportunity to begin to rewire Whitehall fundamentally, allowing us to think, in the long term, about how government should be structured around serving and empowering its citizens. Lord Holmes' 2017 report, Distributed Ledger Technologies for Public Good: leadership, collaboration and innovation, explains how the scene is set for a bigger take-up of this kind of technology.

The UK has already taken a leading role in developing legislative, regulatory and institutional measures that provide a sound legal framework within which DLT development can take place. The Investigatory Powers Act 2016 sets new standards for internet-related law enforcement, while the Data Protection Bill looks beyond the EU's General Data Protection Regulation (GDPR) to create and protect rights in relation to personal data before and after Brexit. The UK is wellplaced to include DLT as a key component in its digital strategy, yielding benefits for national and individual security. ${ }^{40}$

What we need now, therefore, is a more transparently coordinated response to how DLT can aid public-service provision, instead of standalone departmental 'proof of concept' projects. Embracing the opportunities of this technology should be fit explicitly_nominally as well as substantively-into a ministerial brief. And a publicfacing 'Chief Blockchain Officer' should be appointed from within the government's existing taskforce to coordinate the UK's strategy regarding the application of DLT to public services and data. This role could be expanded to include other key new technologies, such as AI, as and when they converge. It will also be essential for the UK to ensure that any regulation in place is appropriately secure, yet sufficiently flexible to allow for world-leading innovation. If regulation is not sufficiently clarified, innovators will be tempted to 
move overseas.

\section{Proposal: the UK 'blockchain departmental target'}

There are many differences that need to be taken into consideration when making comparative points between countries, and serious questions that need to be asked about blockchain and scalability. It is clear, however, that, within an appropriate system, a concerted embrace of blockchain and associated technologiesincluding technologies that are still in the early stages of evolution-could lead to significant savings for the UK Exchequer. Such savings could offer a substantial 'digital dividend' to pass back to taxpayers or reinvest in services.

Government departments should aim to be ahead of the game on these technologies, and premise their takeup on empowering citizens and improving efficiency. Within government, the main direct savings from embracing blockchain would come through reduced transaction and procurement costs, but the potential amount that could be saved is very difficult to calculate, as the majority of studies on such savings implications are industry specific. It is also important to recognise implementation costs, as well as long-run costs in storage and electricity — although future technological advancements should help to reduce these.

The government departments that are likely to benefit most from blockchain-style technologies are those involving a large number of yearly transactions, with local government, HMRC, BEIS, Defra, DWP, and DfT being the major potential beneficiaries. The government's Transactions Explorer, which currently provides transactions data for 782 public services, shows the vast number of transactions that take place. The total volume of government transactions between April 2016 and March 2017 was 3,319,986,524, with the ten largest services by quantity of transactions making up 3,025,295,231 of this (that is, 91 per cent of all transactions). Stamp duty reserve tax transactions alone make up 1,540,077,106 of this figure, whilst 405,544,113 PAYE transactions also took place. ${ }^{41}$ Specifically, blockchain has huge potential for a number of departments, such as Dfid and the MoD, where the transfer of funds, procurement costs, and supply chain monitoring all present high costs.

Calculating potential government savings is difficult at the departmental level, and almost impossible at the overall level. However, a greater focus on such technologies-not only blockchain, but also other associated innovations-would clearly prove transformative. Government departments should lead the way, therefore, and each put in a place a long-term target of making a 1 per cent efficiency saving, by embracing these new technologies. A 1 per cent saving across government would take a great deal of time and effort to implement, although some departments will find such a target much easier to meet than others. For context, however, total managed expenditure for 2017 18 is anticipated to be around $f 802 \mathrm{bn},{ }^{42}$ therefore, a 1 per cent saving would be $f 8 \mathrm{bn}$. A renewed focus on efficiency and the opportunities of new technology would be inspirational in a wider sense, too.

\section{BLOCKCHAIN: HEALTHCARE, FOOD, FINANCING}

So, what could a fuller application of blockchain look like in the UK? How might it be used to unlock some of the main challenges we face today? Here are three example areas for potential UK transformation.

\section{1) Unlocking healthcare}

While change to the healthcare system is inevitably slow, blockchain and associated technologies could have a particularly transformative effect on the NHS. In some areas of the UK, for instance, it is still the case that the results of blood tests are posted to surgeries, before being manually inputted into a patient's record. There are many clear risks in such a system-from results getting lost in the post, to records being coded incorrectly or attributed to the wrong person. It is also costly and inefficient. Now, imagine if everyone had their own NHS record on blockchain or associated similar technology. Blood test results could surely be stored almost instantaneously, for the patient to see, as well as their GP or any other health professionals whom the patient wanted to have access to their data. If everything could be tracked accurately in this manner, a complete picture of the patient's health data would be provided, while removing so much of the current administrative burden. This would surely lead to quicker diagnoses and treatments, with the opportunity to reduce mortality rates.

By embracing blockchain and associated technologies, patients might also be freer to change GPs or seek second opinions. It could also be easier to spot the development of the kinds of diseases that spread across more than one area of expertise, as the data of the patient concerned would be available to all of the healthcare professionals whose access the patient had authorised. Dentists and opticians could potentially have access to more extensive health data, too, and health data from wearable health technology could also be linked in. Each person could have their own complete health record, which they would control themself, meaning that the data that is held relating to health and health decisions would return to patients and their chosen medical professionals.

Imagine a maternity system in which a pregnant woman would no longer have to carry around her written maternity notes, as her data could be accessed-with 
her permission-by any health professional, anywhere in the country. Imagine a health system that used these modern technologies to store information about prescriptions, as well as a patient's full health picture, allowing the future development of customised drugs and medicines. With so many health professionals potentially involved, the use of such technology could lead to a fully integrated and audited system.

In a further embrace of the possibilities of new technologies, people could allow certain AI systems to have access to their data, in order to scan for patterns or problems that would be flagged for them and their doctors. This could be a significant step towards making our healthcare system more preventative and customised, saving both costs and lives.

Of course, blockchain is not the only solution to the challenges above-and other related technologies would have their part to play-but it seems clear that the energy and interest that blockchain has recently aroused could be used to ensure that the public sector reviews its databasing, and seeks to address data sharing and storage in more efficient ways. It is clearly retrograde that we still have systems designed around pieces of paper, and that life-saving data-all too often-is not easily sharable between different parts of the NHS. An increased focus on DLT and associated technologies would also put patient empowerment at the heart of healthcare system reform.

\section{2) Unlocking the food supply chain}

The 'horsemeat scandal' of 2013 arose when horsemeat mixed with beef was discovered to have entered the food supply chain. Overnight, it became increasingly difficult to trust the labels found on food packaging. Food is one of the UK's most heavily-regulated industries, yet these problems continue to arisemost recently in June 2018, when a Daily Telegraph investigation revealed that products labelled as 'vegan', yet containing traces of meat, were being sold at leading UK supermarkets. ${ }^{43}$ Could a combination of DNA sampling and blockchain be used to ensure an end to this?

Imagine if a restaurant diner could zap a burger's QR code, and know in seconds exactly where every one of its ingredients originated. Blockchain could surely make the food supply chain much more transparent and trustworthy. Such technology could be used to show the animals involved in the making of a product, how many times they had been moved during their lifetimes, their welfare conditions and the medicines they had been given, as well as details of the abattoir in which they had been slaughtered, the factory where their meat had been processed, its nutritional information, and more. At the click of a button, or the zap of code, the entire food supply chain could become more verifiable, trustworthy, and the customer would gain new power to demand changes. In the case of food needing to be recalled, the blockchain could tell the food's entire story, meaning potentially serious problems could be isolated within minutes. And, again, blockchain's immutability would provide for a more fool-proof system.

Now, imagine how the same processes and technological advancements might apply with regard to the products that need to be sent across borders. Would we still need physical border infrastructure? Think of a car, with its many components that have been made in many countries. The blockchain could store details of those components and their provenance, along with information pertaining to taxation and customs duties and standards. Likewise, this technology could apply to so many other products. It could improve traceability, reduce costs, strengthen trust, and make customs and duties easier to collect and manage. ${ }^{44}$ Of course, the integrity of these systems ultimately depends on the information used being correct in the first place, but the current checks and balances on the accuracy of this information would not need to be replaced-rather, they could be complimented by the use of blockchain technology.

\section{3) Unlocking financing}

At the extreme of the possibilities on offer, if the Bank of England and HM Treasury were to back a blockchain parallel for our currency, citizens could potentially use digital 'wallets', rather than needing bank accounts. ${ }^{45}$ Then, there would be no need to pay monthly fees, no need to remember sort codes and account numbers, and issues surrounding people needing fixed addresses to access certain opportunities could also begin to be addressed. As a result, people would become freer to control their own money in the way they wanted, without the risk of fraud or theft.

Most simply, however, blockchain offers substantial opportunities to reduce transaction fees for consumers and businesses-although security costs will arise. In 2017, the banking industry estimated that total credit and debit card payment volumes would rise from 14.3 billion payments in 2016, to 21.9 billion in $2026 .{ }^{46}$ Might it be possible to use blockchain and associated technologies to cut the fees on each of those transactions? Reduced transaction costs mean that money can be transferred, borrowed, and lent at lower costs.

The overall costs of international payments could be reduced, for instance, with blockchain allowing someone to transfer money in a process taking only a couple of minutes-no more waiting three to five days for funds to clear! This approach is already being tested, with many international pilots having taken place. HSBC and ING conducted their first live 
commercial trade finance transaction on blockchain in May. ${ }^{47}$ Again, blockchain is not the only new technology revolutionising this space-the UK-based firm TransferWise uses a 'transfer match system', for instance. Competition between technological approaches will only drive down costs further. Soon we may be freer to use our money whenever and wherever we want, without it costing the world.

Finally, lending could be transformed by fusing peerto-peer lending websites with crowdfunding and blockchain technology, to lend mortgages to firsttime buyers or investors, using smart contracts. A new type of ISA, encouraging wealth to be recycled to younger generations, at lower costs, could even be introduced, with minimal fees. Banking experts claim that blockchain is becoming key to a transformation of their industry.

Radical blockchain: unlocking a more efficient and liberal state

But could blockchain be applied even more radically? How might the buyer of a new home in Bloxwich benefit, for instance, if blockchain technology replaced the Land Registry? And what if blockchains were created for pieces of land, in open data form, including details on everything from utilities, geology, underground mapping, minerals, freeholder information, building regulations, and planning permissions? The use of such technology could reduce costs, make conveyancing easier, and make it simpler for consumers to access all of the information relevant to the site they were interested in buying. Homes could be safer, and decision-making easier. There are vast opportunities to be explored here, not least in the current climate regarding younger people's access to housing: could new technologies like blockchain have a deep democratising effect?

Could other public ledgers be replaced in this way, too, to reduce costs and strengthen societal trust? If Universal Credit were delivered via blockchain, for instance, would administrative expenses be substantially reduced? Could vehicle registration, insurance, and taxi licensing be handled via blockchain? Could self-assessment tax returns be automated through blockchain? Could this technology be used to design out costs in the energy network, reducing bills, nationwide? And what might its applications be regarding voting?

Clearly, there are many other possibilities for liberalising the state through the use of blockchain and associated technologies that are yet to be identified. This paper poses wide-ranging questions and suggestions, rather than seeking to design infrastructure. But there is much more to be considered in terms of the opportunities ahead of us, both for business, and in terms of revolutionising individual empowerment regarding our interactions with the state.

\section{CONCLUSION}

Blockchain and associated technologies offer an unrivalled opportunity to begin to review and redesign the UK's data systems. Whitehall and public services could be fundamentally rewired to empower citizens and better serve their needs. We should encourage digital entrepreneurship. We must tackle the trust deficit. By introducing a departmental target for blockchain efficiency savings, we can begin to generate a digital dividend to pass on to tax payers or to reinvest. And we can use a mix of classical liberal values and new technologies to strengthen individual freedom and improve the life chances of all. We must harness the energy of entrepreneurial spirit created by these new world-changing technologies to ensure the future is freer. By engaging now, and recognising blockchain's potential, we can ensure it is used by the state to empower individuals, and to afford us real control over our own data.

\section{Key proposals}

The state should focus its attention on using blockchain to enable social freedom, to increase efficiency, and to rebuild societal trust. The state should not be allowed to use such technology to intrude into the lives of individuals - but rather the technology should be used to empower individuals in their necessary engagements with the state.

An extensive international blockchain competition' should be set up in the UK to drive homegrown entrepreneurship, and to entice leading global players to develop technology here. This should ideally be established in collaboration with leading British universities, and funded by businesses that would benefit from improved national technological standards.

Embracing the opportunities of distributive ledger technology (DLT) should be fit explicitly_nominally as well as substantively-into a ministerial brief. And a public-facing 'Chief Blockchain Officer' should be appointed from within the government's existing taskforce to coordinate the UK's strategy regarding the application of DLT to public services and data. This role should be expanded to include other key new technologies, such as AI, as and when they converge.

Government departments should show leadership by putting in a place a long-term target of making a 1 per cent efficiency saving, by embracing these new technologies. 
A 1 per cent saving across government would take a great deal of time and effort to implement, although some departments would find such a target much easier to meet than others. For context, however, total managed expenditure for 2017-18 is anticipated to be around $802 \mathrm{bn}$ - therefore, a 1 per cent saving would be $f 8 \mathrm{bn}$. A renewed UK focus on efficiency and the opportunities of new technology would be inspirational in a wider sense, too.

From the outset, we have been extremely keen for FREER to promote the kinds of technological advancement that offer great opportunities for increased economic progress alongside increased individual freedom. EH1 exciting and readable paper makes it very clear that blockchain is one of those opportunities. When, last month, EH1 spoke so enthusiastically about this paper at PMQs, the Prime Minister thanked him, and suggested that he 'might like to distribute the work that he's done to all members of this house'. We shall, therefore, take the Prime Minister's advice, and send all MPs a digital copy of Unlocking Blockechain. We are extremely grateful, too, to the many people who have offered advice about blockchain or commented on draft versions of this paper, including Alexander Barnes, Martin Blatchford, Dave Birch, Mike Flower, Rachel Finley, Iqbal Gandham, Bhavin Kotecha, Peeter Kokek, Michael Mainelli, Catherine McBride, Sue Milton, Stephen Talbot, and Naseem Naqvi and Jane Thomason from the British Blockechain Association. Any errors, however, are the responsibility of EH1 and FREER.

'https://www.ibm.com/blogs/insights-on-business/consumerproducts/2-5-quintillion-bytes-of-data-created-every-day-how-doescpg-retail-manage-it/

${ }^{2}$ https://www.forbes.com/sites/jasonbloomberg/2018/02/24/ dont-let-blockchain-cost-savings-hype-fool-you/\#7d09bf455811

${ }^{3}$ https://www.cognizant.com/whitepapers/retail-opening-thedoors-to-blockchain-codex2879.pdf

${ }^{4}$ https://www.accenture.com/gb-en/insight-banking-on-blockchain

${ }^{5}$ https://www.finextra.com/finextra-downloads/newsdocs/the $\% 20$ fintech $\% 202 \% 200 \% 20$ paper.pdf

${ }^{6}$ https://nordic.businessinsider.com/sweden-is-pioneering-ablockchain-run-land-registry---which-could-save-taxpayers-\$100million-2017-4/

7https://smartdubai.ae/en/Initiatives/Pages / DubaiBlockchainStrategy.aspx

${ }^{8}$ https://missblockchain.tech/2018/05/22/unchain-the-blockspeed-transparency-and-efficiency-in-donor-fund-flows/

${ }^{9}$ (It is important to recognise the difference between automation related to $\mathrm{AI}$ and automation related to smart contracts. AI often lacks algorithmic and data transparency, which can lead to criticisms about bias; smart contracts follow auditable and transparent rules.)

${ }^{10}$ https://e-estonia.com/wp-content/uploads/faq-a4-v02blockchain.pdf

${ }^{11}$ https://e-estonia.com

${ }^{12}$ https://guardtime.com/technology

${ }^{13}$ https:/ / cyware.com/news/estonias-guardtime-delivers-aspecialised-cyber-exercise-for-the-uk-civil-nuclear-sector-0ce903ee

${ }^{14}$ https:/ /e-estonia.com/how-save-annually-820-years-of-work/

${ }^{15}$ https://rhulgeopolitics.wordpress.com/2017/11/17/lessonsfrom-the-land-of-e-government-digital-trust-and-accountability/

${ }^{16} \mathrm{https}$ // /www.valitsus.ee/en/news/prime-minister-juri-ratassspeech-web-summit-technology-conference-8-november-2017

${ }^{17}$ https://www.ipinst.org/2016/05/information-technology-andgovernance-estonia\#1

${ }^{18}$ https://www.inverse.com/article/13212-estonian-prime-ministertaavi-rivas-makes-a-splash-on-the-daily-show

${ }^{19}$ https://www. forbes.com/sites/kalevleetaru/2017/09/11/ estonias-id-card-and-the-march-of-cryptography

${ }^{20}$ https://www.zdnet.com/article/estonias-id-card-scrisis-how-estates-poster-child-got-into-and-out-of-trouble/

${ }^{21}$ http://www.legislation.gov.uk/ukpga/2000/7/section/7

${ }^{22}$ According to Jaan Priisalu and Rain Ottis, 'Personal control of privacy and data: Estonian experience', Health Technology 7 (2017), 441-451, 'By default medical specialists can access data, but any patient can choose to deny access to any case related data.' See also $\mathrm{p}$. 449 of: https://www.ncbi.nlm.nih.gov/pmc/articles/PMC5741780/ pdf/12553_2017_Article_195.pdf

${ }^{23}$ https://medium.com/the-mission/blockchain-adoption-ingovernment-79c54a18c3c9

${ }^{24}$ https://businesstimes.com.sg/technology/singapore-to-launchfirst-digital-trade-platform-for-smes-using-blockchain-technology

${ }^{25}$ https:// cryptoren.com/uae-blockchain-strategy-2021/

${ }^{26}$ https://google.co.uk/amp/s/www.wsj.com/amp/articles/dubaiaims-to-be-a-city-built-on-blockchain-1493086080

${ }^{27}$ https://smartdubai.ae/en/Media/Lists/Stories/DispForm. aspx?ID $=111$

${ }^{28}$ http://www.dubaifuture.gov.ae/our-initiatives/global-blockchaincouncil/

${ }^{29}$ https://gulfnews.com/news/uae/government/dubai-aims-to-becompletely-paperless-1.2168823

${ }^{30}$ https://www.futureblockchainsummit.com/news/dubai-landdepartment-becomes-worlds-first-government-entity-to-conductall-transactions-through-blockchain-network

${ }^{31} \mathrm{ibid}$

${ }^{32}$ https://www.coindesk.com/uk-government-lures-distributedledger-projects-26-million-fund/

${ }^{33}$ http://www.cityam.com/246605/uk-government-now-has-itsfirst-official-blockchain 
${ }^{34}$ https://www.fnlondon.com/articles/blockchain-startup-hits-therocks-after-owner-spat-20170725

${ }^{35}$ https://www.parliament.uk/business/committees/committeesa-z/commons-select/treasury-committee/news-parliament-2017/ digital-currencies-17-19/

${ }^{36}$ ibid.

${ }^{37}$ http:/ / researchbriefings.parliament.uk/ResearchBriefing/ Summary/POST-PB-0027

${ }^{38}$ https://www.gov.uk/government/speeches/matt-hancockspeaking-at-the-london-blockchain-conference

${ }^{39}$ https://ec.europa.eu/digital-single-market/en/news/europeancountries-join-blockchain-partnership

${ }^{40}$ http://chrisholmes.co.uk/wp-content/uploads/2017/11/ Distributed-Ledger-Technologies-for-Public-Good_leadershipcollaboration-and-innovation.pdf

${ }^{41}$ Data can be found in 'transaction-volumes-3.csv' at https://www. gov.uk/performance/services

${ }^{42}$ https://www.gov.uk/government/publications/autumn-budget2017-documents/autumn-budget-2017

${ }^{43}$ https://www.telegraph.co.uk/news/2018/06/08/supermarketscandal-pork-turkey-found-vegan-meat-free-meals/

${ }^{44}$ (Organisations such as Long Finance and Distributed Futures are currently working on how 'Smart Ledger technology' —or 'mutual distributed ledgers' - might facilitate global trade. Their recent report, The Economic Impact of Smart Ledgers on World Trade, claims that this technology offers 'particular advantages in solving some of the problems that might emerge from Brexit'.)

${ }^{45}$ (This idea only features as a brief example in this paper, but it should be noted that such moves substantially change the role of central banks.)

${ }^{46}$ UK Cards Association Report UK Card Payments 2017

${ }^{47}$ https://www.gtreview.com/news/fintech/hsbc-and-ing-in-livetrade-finance-transaction-on-blockchain/ 